\title{
Alfabetización para una cultura social, digital, mediática y en red
}

Nieves González Fernández-Villavicencio*

"Cuando creíamos que teníamos todas las respuestas, de pronto, cambiaron todas las preguntas".

(Frase atribuida a Mario BENEDETTI)

Resumen: Las tecnologías están cambiando el concepto de alfabetización y las competencias básicas necesarias para considerarse alfabetizado en una cultura digital y en red. Nuevas competencias mediáticas, críticas, tecnológicas, sociales, vienen a redefinir la propia necesidad de estar alfabetizado y por ende, en información, hasta el punto de exigir un término como Alfabetización digital, que aglutine las nuevas competencias, y centre más su objetivo en la formación que necesitan los individuos y menos en los colectivos profesionales implicados en esa formación. Se presentan diversos ejemplos, dentro y fuera de nuestro país, de iniciativas llevadas a cabo preferentemente por bibliotecas, en los campos de la alfabetización digital y la generación de contenidos digitales locales.

Palabras clave: Alfabetización informacional, ALFIN, alfabetización digital, competencias digitales, alfabetización mediática, alfabetización digital y mediática, alfabetización mediática e informacional, biblioredes, plan Alba, CI2, contenidos digitales locales.

\section{Literacy for a networked and digital social culture}

Abstract: Technologies are changing the concept of literacy and of the basic skills necessary to be considered literate in a digital and networked culture. New critical, technological and social skills redefine the need to be literate and, as such, for information literacy. This requires a new term, such as Digital Literacy, in order to include the new skills and to focus more on the training of individuals rather than on the professional groups involved in the training. Several examples are presented, both within our country and beyond, of initiatives undertaken by libraries in digital literacy and in the generation of local digital content.

Keywords: Information literacy, InfoLit, digital literacy, digital skills, media and digital literacy, media and information literacy, biblioredes, Plan Alba, CI2.

* Universidad P. de Olavide. Sevilla.

Correo-e: nievesglez@gmail.com

Recibido: 19-12-2011; 2. ${ }^{a}$ versión: 26-01-2012; aceptado: 06-02-2012. 


\section{Introducción}

Es sabido que la tecnología siempre ha definido la alfabetización. Antes de la imprenta, lo que definía la alfabetización era la oralidad, la capacidad para transmitir ideas y pensamientos e información, a través de la voz. Hoy día, el concepto vuelve a cambiar en un mundo saturado de medios, donde las TIC son en parte, responsables y protagonistas de la transformación de la Sociedad de la Información en la que nos hallamos inmersos. Toda nuestra actividad social y cultural está mediatizada por este tipo de tecnologías y los nuevos medios requieren de nuevas alfabetizaciones.

Cada vez que aparece una nueva tecnología de la información y la comunicación, acaba modificando la forma en la que se estructura y procesa el pensamiento. Prueba de ello es el libro, "el artefacto cultural que mejor representa la forma de pensamiento secuencial en que hemos sido socializados y educados en la sociedad industrial. La irrupción de la tecnología digital, asociada a la conexión de dispositivos móviles multimedia y el desarrollo de las redes telemáticas han generado nuevas formas de acceder, construir y comunicar el conocimiento" (Lara, 2011a)

Los cambios en las TIC afectan también a los sistemas formales de enseñanza, sistemas que llegan a cuestionarse en el marco de la Sociedad en Red, definida por un entorno de información abundante, numerosas oportunidades para la interacción social y el aumento de dispositivos personales para la producción de conocimiento. (Lara, 2011b). Las nuevas generaciones son nativas de estas tecnologías, y ejercen una gran capacidad para manejar dispositivos, sin embargo, reflejan cierta dificultad para gestionar información de diversa naturaleza, o para tener experiencias más satisfactorias en torno a sus prácticas digitales, tanto en la evaluación de la credibilidad de la información, en la construcción de su identidad digital o en la gestión de la privacidad. "Es ahí donde la educación formal puede colaborar introduciendo habilidades de competencia digital que ayuden a los jóvenes a desenvolverse y generar sentido del entorno tecnosocial en el que viven" (Lara, 2011a). Sin embargo, el lugar en el que se están produciendo los mayores cambios en el terreno de la educación, no son las escuelas ni tampoco lo son las bibliotecas. (Prensky, 2011).

Según la UNESCO, el mismo concepto de analfabetismo ha tenido una irremediable transformación a través del tiempo. Al aumentar las exigencias para la sociedad, saber leer y escribir ya no es suficiente. Cuando las TIC irrumpieron en los primeros años noventa del siglo pasado, se empezó a hablar de la necesidad de una alfabetización digital para aprender a utilizar las tecnologías que estaban emergiendo. Desde entonces, la definición de qué se entiende por alfabetización digital, qué competencias requiere y cómo adquirirlas, se ha enfocado principalmente desde dos planos distintos: uno, centrado en el componente más tecnológico y otro, centrado en su aspecto más comunicativo, social y participativo. 
Popularmente se ha identificado ser alfabeto digital con saber usar las tecnologías y dispositivos de forma instrumental, identificando este concepto con las competencias tecnológicas o informáticas. Sin embargo, con el tiempo, la definición de alfabetización digital ha dejado de tomarse como relativo a la tecnología para considerar una alfabetización más general, que integra todas las competencias que una persona necesita para desenvolverse de forma eficaz en la Sociedad de la Información. El concepto se amplia para significar estar alfabetizado "en y para la cultura digital" (Lara, 2011a).

Esta sociedad actual cuenta efectivamente con un componente tecnológico muy fuerte, pero además exige unas formas diferentes de participar, comunicarse y colaborar en la red, características que por otro lado, modifican sustancialmente las llamadas competencias informacionales (ALFIN).

\section{Las competencias tecnológicas en España}

Durante los últimos años hemos asistido a un crecimiento sin precedente en el desarrollo de la Sociedad de la Información desde el punto de vista de las tecnologías. Esta evolución ha sido posible gracias a diversos factores como el desarrollo de infraestructuras, la evolución de los dispositivos y sobre todo el creciente interés por el uso de los servicios por parte de los ciudadanos. En el Informe de la Sociedad de la Información en España, 2010, de la Fundación Telefónica (http://e-libros.fundacion.telefonica.com/sie10/) se observa cómo la digitalización de la vida de las personas y la adopción de Internet como instrumento habitual en las actividades diarias, no se está produciendo de una forma homogénea en la sociedad, como puede ser el caso de los más jóvenes, con ratios del 80\% en la utilización de Internet. Sin embargo, el segmento de población entre 45 y 64 años, muestra datos superiores a la media en el aumento de actividades usando Internet, y lo mismo ocurre con el segmento de población entre 55 y 64 años.

Este proceso de rápida adopción por parte de sectores más jóvenes de población y posterior aceptación de las capas más maduras, es un patrón que parece repetirse en el tiempo, lo que nos hace pensar que actividades que ahora son comunes entre los jóvenes como la utilización de las redes sociales como mecanismo de comunicación, se harán habituales para el resto de la sociedad en los próximos años.

En la encuesta del INE sobre el uso de Internet en España, de 2011 (http://www.ine.es/inebmenu/mnu_tic.htm), la conclusión es clara, la brecha digital entre generaciones existe, es bastante importante, pero lo más llamativo de esta gráfica es observar la velocidad a la que disminuye, ya que los ciudadanos son cada vez más conscientes de la utilidad del uso de estos servicios en sus actividades cotidianas. 
FIGURA 1

Disminución de la brecha digital en España entre tramos de edad

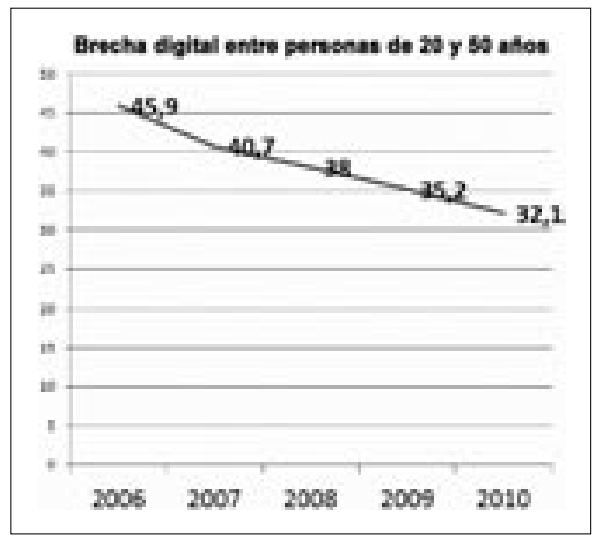

Reelaboración de gráfico a partir de (http://www.hijosdigitales.es/2011/06/el-uso-de-internet-en-espana-y-la-brecha-entre-generaciones/).

En cuanto a los hábitos y consumo de contenidos digitales por parte de los españoles, según el Informe sobre la Industria de los contenidos digitales en España, de 2011 (http://www.cedro.org/docs/documentos/informe_contenidosdigitales2011.pdf?Status=Master) los datos son también muy elocuentes:

- El 91,5\% de los españoles consumió algún tipo de contenido digital, sea en línea o con un dispositivo no conectado a Internet en 2011.

- El 27,2\% de los españoles lee revistas, periódicos o libros online diariamente y el 43,7\% de los españoles declara que ha reemplazado esta actividad, al menos en parte, por el formato digital.

- Escuchar música o radio (35,9\%), comprar CD (26,8\%) y ver televisión gratuita (24,2\%), son otras de las actividades con mayor grado de reemplazo.

Según el Informe eEspaña de Orange 2011 (http://fundacionorange.es/fundacionorange/analisis/eespana/e_espana11.html), los españoles no solo consumen contenidos digitales, sino que tambien los producen, pasando de un 8\% en 2008 a un $27 \%$ en 2010. En cuanto al tipo de contenidos que suben a la red, se trata mayoritariamente de fotos (42'75\%), textos (29'15\%), vídeos (12’08\%), o música (6’97\%). Estos contenidos digitales se están generando principalmente usando plataformas de edición de la web social o web 2.0

En cuanto al uso de las redes sociales en España, del informe IAB/Spain (Interactive Advertising Bureau/Spain), de noviembre de 2011 (http://www.iabspain.net/descargas/descarga.php?id=173), se desprende que el 75\% de los individuos conectados en 2011 es usuario de las redes sociales. Este aumento ha sido menor en 2010 (un 7\%) que en 2009 (un 37\%), lo que indica que el crecimiento tiende a estabilizarse. 
FIGURA 2

Evolución de los usuarios de las redes sociales (Informe eEspaña de Orange)

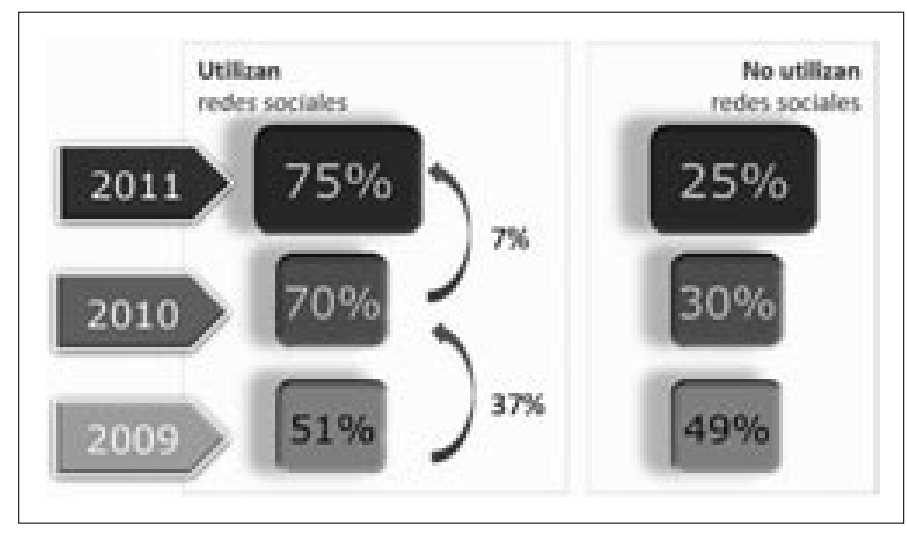

Los individuos conectados pero que no son usuarios de las redes sociales, aducen falta de interés (algo que aumenta con la edad), o falta de privacidad. Entre los que son usuarios de las redes sociales, aumenta la frecuencia de su uso, en un promedio de 6 veces por semana.

\section{La alfabetización digital y/o mediática}

Ante este avance continuo y generalizado en el uso de las tecnologías, las redes sociales y la participación y generación de contenidos por parte de los propios ciudadanos, muchas son las voces y los informes que se alzan para señalar que el uso de estas tecnologías no vuelve alfabetos digitales a los internautas. En este sentido se pronuncia la edición anual del NMC Horizon Report 2011 para la Educación Superior (http://www.nmc.org/pdf/2011-Horizon-Report.pdf). Este proyecto fue lanzado en 2002 y traza el panorama de las tecnologías emergentes para la enseñanza, la investigación del aprendizaje, la investigación creativa, y la gestión de la información. Gran parte del trabajo del proyecto está orientado a investigar, identificar y describir las tecnologías emergentes que puedan tener un impacto considerable en la enseñanza, el aprendizaje y la expresión creativa en la educación superior, con un horizonte de uno a cinco años.

En relación al mayor reto crítico que este proyecto detecta para los próximos años, se encuentra la Digital Media Literacy, Alfabetización digital y mediática, que continua su ascenso como competencia clave en cada disciplina y profesión. El informe señala que, aunque exista un consenso general acerca de la vital importancia que esta competencia tiene en la vida de los estudiantes, sin embargo no se encuentra integrada en los currículos académicos. El reto se ve agravado 
por el hecho de que las tecnologías digitales se transforman y cambian rápidamente a un ritmo que supera en general el desarrollo del currículo.

Por otro lado, el Informe Horizon contempla también como aspecto crítico, mantenerse al día ante la abundancia de información y de herramientas tecnológicas e interfaces diversas, lo que constituye un nuevo reto tanto para profesores como alumnos. La explosión de los contenidos generados por los usuarios, que aumenta el número de ideas, opiniones, información de todo tipo, agravan la necesidad, hoy más que nunca, de tener herramientas y filtros que nos ayuden a encontrar, interpretar, organizar y recuperar datos de interés. Esta necesidad es un fiel reflejo del impacto de la tecnología en cada aspecto de nuestra vida. Constituyen evidencias del cambio de naturaleza de la forma en la que nos comunicamos, accedemos a la información, nos conectamos con colegas y amigos, aprendemos e incluso, la forma en la que nos socializamos.

FIGURA 3

Nube de etiquetas de la Educación mediática (Web de educación mediática http://www.educacionmediatica.es)

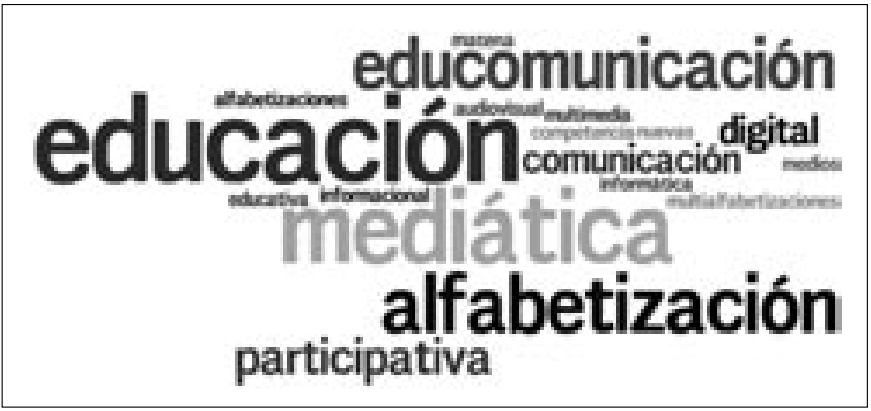

Con el término alfabetización digital mediática (http://www.reclaimthemedia. org/digitalmedialiteracy) se destaca el uso de distintos medios frente a lo puramente textual y se define como la habilidad para acceder, analizar, evaluar y crear diferentes tipos de media. A esta definición se añaden además y más recientemente, una lista de habilidades relacionadas con los medios sociales, como la naturaleza interactiva de la producción y consumo de medios, en concreto la habilidad para colaborar y participar. Implica tambien un cambio en la forma en la que accedemos, analizamos y evaluamos los media, ya que la web nos ofrece muchas posibilidades para elegir información, noticias, y entretenimiento, y complica el panorama de los media con publicidad y tácticas de marketing.

Potter (2010), destaca la dificultad para definir esta competencia y el poco acuerdo existente entre los autores, ya que unos la relacionan fundamentalmente con la capacidad crítica, y otros lo convierten en un paraguas bajo el que tienen cabida todas las competencias. 
De su actualidad habla la frecuencia con la que este término aparece en los medios sociales digitales, convirtiéndose en un trending topic en redes sociales como Twitter. En herramientas como Google Trends, podemos ver como el término "media literacy" se ha mantenido por debajo a lo largo de los últimos años, pero superando ya, a otro más consolidado como "information literacy", y el nuevo "digital literacy", de muy reciente aparición en el buscador, aparece superando en popularidad a los dos anteriores.

\section{FIGURA 4}

\section{Comparación de los términos en Google Trends}

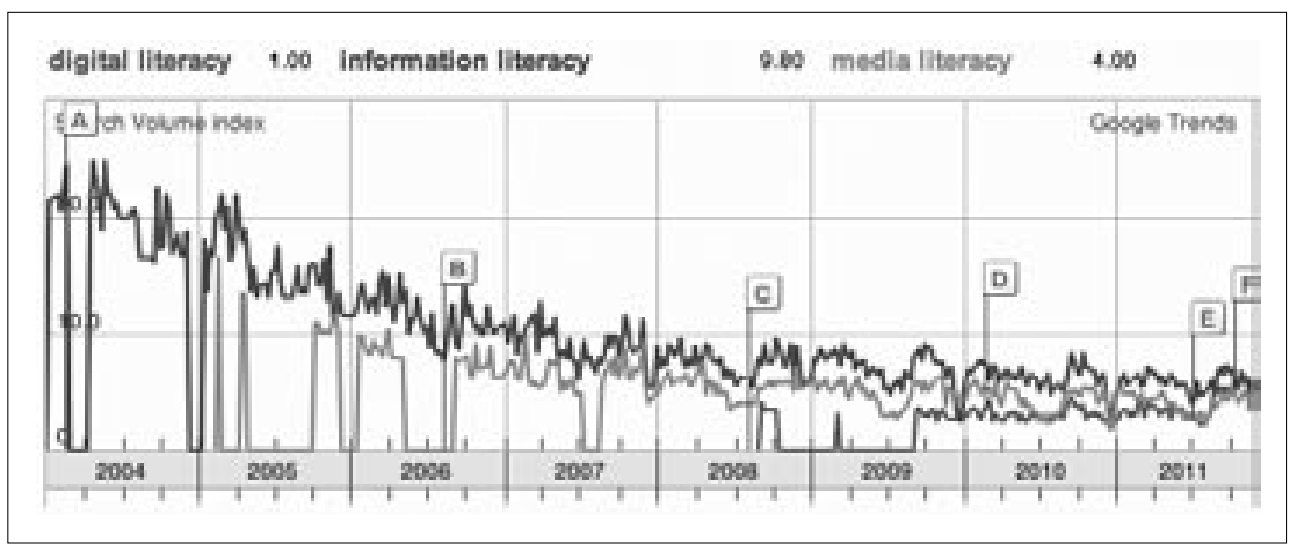

La UNESCO ha optado en los últimos años por evitar el término "digital" y se decanta por utilizar una solución compuesta de los términos «información» y "medios" (Wilson y otros, 2011), uniendo las dos alfabetizaciones en una sola, para impulsar lo que denominan "destrezas y habilidades para la alfabetización crítica, la evaluación y el uso de la información y los medios en la vida profesional y personal" (Lara, 2011a). En este sentido y desde el año 2010, la UNESCO ha trabajado en el desarrollo de un conjunto de indicadores para la alfabetización mediática e informacional, Media and Informational Literacy, MIL, que incluye otras muchas alfabetizaciones como la tecnológica, digital, en bibliotecas, en Internet, en noticias, etc. (Moeller y otros, 2011). Dentro del mismo programa, la UNESCO y la UNAOC (Alianza de civilizaciones de las Naciones Unidas) han creado la UNESCO UNITWIN UNAOC, red de Universidades para la Alfabetización mediática e informacional y el dialogo multicultural (UAC-MILID), entre las que se encuentra la Universidad Autónoma de Barcelona. Esta misma Universidad mantiene el espacio web, Gabinete de Comunicación y Educación (http://www.gabinetecomunicacionyeducacion.com/), que participa de forma muy activa en el fomento de las estrategias de alfabetización mediática. 


\section{4. ¿Qué competencias demanda la sociedad?}

Ya avanzábamos qué significaba estar alfabetizados en la sociedad actual y cómo el mismo concepto de analfabetismo ha tenido una irremediable transformación a través del tiempo. No hay que perder de vista que el objetivo de esta competencia era permitir la comunicación efectiva y por lo tanto, implica tambien la idea de participación en la sociedad.

En este sentido, David Warlick (2008), aboga por una definición de alfabetización más amplia y flexible, más abierta. Para poder comunicarse de forma efectiva, y participar en la sociedad que nos ha tocado vivir, hay que tener competencias visuales, digitales, mediáticas, informáticas e informacionales. Este mismo autor se replantea y redimensiona el concepto de alfabetización a la luz de las siguientes preguntas:

1. ¿Qué se necesita saber cuando la mayor parte del conocimiento está a golpe de clic?

Corea del Sur acaba de anunciar que está planificando la digitalización de todos los materiales necesarios para la educación primaria y secundaria (Prensky, 2011). Esto unido a la reducción de los precios de los lectores electrónicos como el de Amazon, que ya vende concretamente más libros en formato electrónico que impreso, hace pensar en una sociedad sin libros en papel. Las bibliotecas universitarias en todo el mundo (Breeding, 2011), aumentan sin cesar sus colecciones electrónicas, en detrimento de las impresas y el préstamo en este tipo de bibliotecas, sube considerablemente gracias a la descarga de materiales en soporte electrónico.

Gran parte de los contenidos que los estudiantes necesitan para sus clases está ya en soporte digital, y avanzamos en una carrera contra reloj. Pero no se trata tan solo de materiales que se encuentran en otro soporte, sino de materiales enriquecidos, accesibles desde distintos tipos de dispositivos, que combinan la información a partir de distintos medios, y procedencias, propias y ajenas, con características sociales como define Prensky (2011) y para el que ya se está desarrollando software específico.

La forma de acceder y usar la información tambien ha cambiado drásticamente, los sitios y redes sociales han transformado el proceso de búsqueda de información y la forma y velocidad con la que la generamos y compartimos, independientemente del tiempo y lugar, independientemente del dispositivo.

2. ¿Cómo distingues entre una buena y mala información? ¿Cómo se evalúa la información cuando cualquiera es generador de contenidos?

La capacidad global de publicar que tiene cualquier usuario con conexión a Internet en la web social, donde se unen tecnología y usos creativos de la misma, 
ha dado lugar a una cultura de la remezcla donde los individuos reaccionan y entran en diálogo con la información que reciben a partir de la reinterpretación y reelaboración de los datos, hasta el punto de poner en cuestión temas como la autoría o la propiedad intelectual (Garaizar, 2011). La fusión de fuentes, canales, medios, mensajes y públicos redunda también en que cada vez nos encontremos con más casos de montajes y bulos que circulan a través de los medios con muy diversos objetivos, desde provocar el pensamiento crítico hasta técnicas de marketing o la simple mentira.

"Cada vez resulta más crítico exigirle al ciudadano una actitud de reflexión y una formación en criterios de verificación de la certeza de la información que utiliza, como actitud ante el aprendizaje a lo largo de toda su vida, ya que Internet se ha convertido en un medio tan "natural" que cuanto más se usa más confianza genera y menos se comprueba la fiabilidad de la información que se obtiene" (Lara, 2011a).

Para Celaya (2011), el hecho de que cualquier persona pueda aportar información u opinión gracias a la facilidad de las nuevas tecnologías sociales web 2.0, genera un amplio rechazo entre algunos miembros del sector cultural, debido al supuesto escaso criterio que tienen la mayoría de las personas para contribuir en cualquier proceso de intercambio de conocimiento. Sin embargo, no debemos olvidar, que también se publican cada año miles de artículos en los medios tradicionales con abundante ideología entre líneas, imprecisiones en datos y abundantes erratas, sin detenernos en hablar de los conocidos fraudes de la ciencia. Todas las tecnologías tienen sesgo, incluida el papel, por lo que se deben conocer los intereses comerciales, ideológicos y sociales que se encuentran detrás de cada una de estas herramientas.

Las competencias intelectuales necesarias para interactuar con la cultura líquida de la web social, de forma crítica y reflexiva, tal y como señala Area (2011), deben adquirirse más allá del mero aprendizaje de las herramientas sociales.

Por otro lado, la web 2.0, los sitios y redes sociales, potencian nuevas formas de verificación y validación de la información, basada en gran medida en el poder de la recomendación: número de "Me gusta", "No me gusta", valoraciones, etiquetas, retwiteos, votos, seguidores e influenciadores, aportan valor a los contenidos y constituyen auténticos sistemas de validación social en Internet. Los comentarios constituyen una forma de medición cualitativa y el liderazgo, la notoriedad, la transparencia, la fidelidad o la influencia, están llegando a ser considerados indicadores estándar de fiabilidad.

\section{3. ¿Cómo abordar los temas éticos cuando formamos a nuestros estudiantes en estas competencias?}

Los temas éticos y legales se deben entender desde la óptica de la realidad actual y no desde la política y los intereses comerciales de los países más poderosos. Los conceptos de derechos de autor, las licencias Creative Commons, 
los temas de plagio y remezcla de contenidos, la facilidad de copiar y pegar desde la red, suben a un primer plano en una cultura de la remezcla, que se revela frente a la propuesta cerrada de la industria cultural.

"Los avances tecnológicos y culturales sientan las bases para pasar de una cultura de sólo lectura a una cultura de lectura-escritura en la que la agregación, modificación y remezcla de contenidos previos constituyen técnicas básicas deseables para una alfabetización digital apropiada. Teniendo en cuenta todo lo anterior, resulta sencillo entender el comportamiento de millones de personas en la Red, al margen de caducos modelos de creación cultural» (Garaizar, 2011).

\section{4. ¿Cómo afecta todo esto a una identidad digital creciente?}

La gestión de la identidad digital constituye una nueva habilidad que hay que integrar en el conjunto de las competencias básicas. La construcción de una identidad y reputación digital en la red implica un aprendizaje y una actitud colaborativa y participativa en la cultura digital y se convierte en un escalón más dentro de la alfabetización digital (Giones, 2010).

En relación a la identidad digital, Lara (2011a) considera que el espacio virtual permite al usuario construirse identidades digitales múltiples y de dominio público, que debe saber gestionar y al mismo tiempo ser consciente del alcance y difusión e impacto de las actuaciones que lleve a cabo en torno a los mismos y que pueden afectar a su propia privacidad y a la de otras personas. Esto resulta evidente en relación al uso que de los medios audiovisuales y redes sociales realizan los más jóvenes, en un ambiente que ellos consideran íntimo y controlado. Sin embargo se observa que la conciencia de la privacidad y reputación digital está aumentando en los más jóvenes y también en el resto de los usuarios de la web social, como pone de manifiesto un reciente informe de Pew Internet and American Life "Teens, kindness and cruelty on social network sites" (http://pewinternet.org/Reports/2011/Teens-and-social-media.aspx) la mayoría de los intercambios de información entre los jóvenes en las redes sociales, no se está produciendo a la vista de todo el público y están adoptando medidas para controlar su privacidad en línea.

A la vista de las cuestiones planteadas por Warlick (2008) que hemos ido comentando en los párrafos anteriores, se impone una revisión de las competencias básicas que demanda la sociedad de la Información digital, social y en red, para todos sus individuos, y en las que nos detendremos a continuación, a la luz de las aportaciones de distintos expertos en este tema:

a) Rainie (2011), director del Proyecto Pew Internet and American Life, enumera las nuevas necesidades de alfabetización que están surgiendo en la sociedad actual, entre las que destacamos la contextualización: "Aprender a contextualizar es una competencia clave en el ecosistema mediático actual. Un mismo mensaje nos puede llegar en forma de 140 caracteres en Facebook, originado 
previamente en Twitter y lanzado por el blog de un medio. Saber leer ese mensaje fuera de su ubicación y entender los nuevos códigos de lectura (ya sean de índole técnico o de índole semántico, desde qué significa un RT o qué implica ver unos puntos suspensivos, o los emoticones), es imprescindible para tomar decisiones rápidas y comprender la esencia del mensaje aun fuera de su contexto nativo.

b) Lara (2011a) propone una serie de competencias imprescindibles en un entorno en red como el actual y desde un enfoque mediático, comunicativo, social, participativo y cívico:

1. Reutilizar la información: localizar, filtrar y sintetizar conocimiento ya producido y distribuido en la Red; aprender a citar y reconocer el valor del trabajo de los otros en su participación a la cultura común.

2. Reinterpretar la información: reconstruir, renovar, reciclar, recuperar; reconstruir discursos propios a partir del conocimiento distribuido; avanzar en nuevas interpretaciones y puntos de vista.

3. Devolver, compartir la información: publicar y divulgar los pensamientos y obras propias, compartir el conocimiento generado y ponerlo en diálogo con el resto de voces de la Red. El aprendizaje bajo este prisma se vuelve social, más que individual.

c) Kelly, uno de los expertos del último informe de la OCLC (2011) enumera los seis nuevos verbos que se necesitan para considerarse un alfabeto digital:

- Leer en pantalla. Nuestra cultura ha sido la cultura del libro, sin embargo nos estamos convirtiendo en seres pegados a pantallas que nos rodean continuamente. Este es el contexto en el que se van a publicar los nuevos contenidos.

- Interactuar. Nuestras expectativas son las de interactuar con los contenidos intelectualmente, pero dentro de poco, tambien físicamente. Interactuamos con la voz, gestos, manos y de forma no lineal.

- Compartir. Toda nuestra actividad mediática se vuelve social: lectura social y libros que se entrecruzan en bibliotecas compartidas.

- Acceder. Ya no se habla de propiedad, el futuro de los media es el acceso y no su propiedad: ¿qué sentido tiene la propiedad cuando se puede acceder a la información en cualquier momento?

- Fluir. Los datos circulan en streaming, sin parar. El paradigma de la página está llegando a su fin. En su lugar los relatos y la información se reconstruyen constantemente. Nos estamos moviendo de lo estático al permanente fluir, como ocurre con Twitter, las RSS feeds, los muros de Facebook, los blogs, la geolocalización, etcétera.

- Generar. La generación de contenidos en distintos formatos y a través de nuevas vías y medios. 
d) Cobo (2011), afirma que hoy día nos enfrentamos a tres alfabetismos básicos: compartir conocimiento, crear contenidos y saber interpretar, traducir e integrar en los entornos de aprendizaje propios. Los elementos que los constituyen son la administración de la atención, la búsqueda y consumo crítico de contenidos, la evaluación y la síntesis, la exportación de formatos, lenguajes y contextos, la creación de contenidos de valor (contextual), la distribución (conexión) del conocimiento y la apertura inteligente (flexibilidad, licencias).

Todos estos elementos se integran en los entornos personales de aprendizaje, y constituyen los requerimientos básicos de la forma en la que aprendemos y nos comunicamos en la red, realidades que están siendo profundamente debatidas por muchos sectores profesionales, profesores, educadores, pedagogos y tambien bibliotecarios.

En este sentido, el próximo congreso de profesores de 2012, "Engaging Students with Teaching, Technology, and Transliteracy" (http://threetees.weebly. $\mathrm{com} /$ ), ha puesto el énfasis en la Transliteracy, más allá de las alfabetizaciones. La forma en la que los estudiantes aprenden en la red, es un tema profundamente debatido, en el que destaca la construcción de los entornos personales de aprendizaje, donde se unen tecnología y nuevos modelos creativos e innovadores de formación.

De igual manera, en las conclusiones del Congreso Internacional "Educación mediática y competencia digital", celebrado en Segovia, en octubre de 2011 (http://www.educacionmediatica.es/congreso2011/), se expone lo siguiente: "Las competencias tradicionales de la educación, saber leer, saber escribir, saber numerar, se han ampliado a la capacidad de comprender, de ejercer la crítica y de desarrollar la creatividad. La alfabetización mediática o educación en competencia mediática, implica el conocimiento de las técnicas, de los instrumentos tecnológicos y de las posibilidades del software, de los lenguajes específicos y de sus funciones informativas, expresivas y educativas; implica también el conocimiento y capacidad para indagar en las viejas y nuevas fuentes de información y en el aprendizaje de las formas de participación en las redes sociales y en contextos virtuales que implican juegos, simulaciones, etcétera".

Para entender el alcance de estas nuevas alfabetizaciones, nada mejor que reflexionar sobre las siguientes preguntas: ¿Cómo es nuestro sistema de aprendizaje personal? ¿De qué forma aprendemos, buscamos, seleccionamos, y procesamos la información, de qué manera la comunicamos y compartimos? Ese es el origen del mapa mental "Procesar la información" que se presenta a continuación y en el que Francis Pisani, conocido bloguero y columnista de El País y Le Monde, invitó a colaborar a la autora de este artículo, como forma de dar respuesta a las preguntas anteriores (Pisani y González, 2011). En este mapa aparecen reflejadas todas las competencias o alfabetizaciones de las que hemos venido hablando a lo largo de este artículo: competencias informacionales que actúan de brazo vertebrador, aunque redefinidas y redimensionadas, y que articulan tec- 
nologías de la web social, potencian la actitud crítica y reflexiva, incluyen multimedia y trabajo colaborativo, contemplan las distintas formas de reutilizar e interpretar la información, y de interactuar con las comunidades, en sistemas flexibles de comunicación.

FIGURA 5

Fragmento del Mapa mental Procesar la Información

(Pisani y González, 2011)

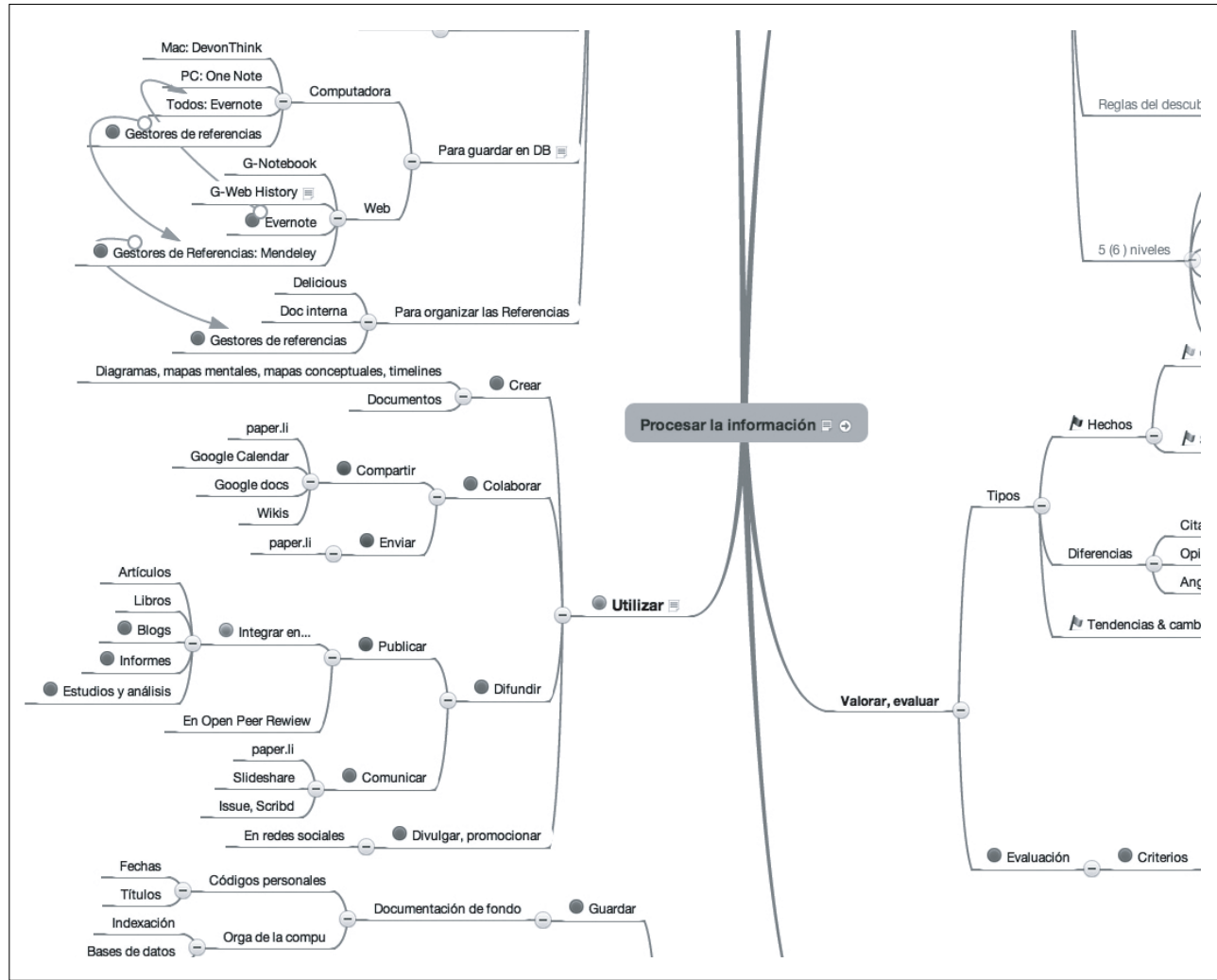

Esta nueva forma de trabajar, de informarse, de interactuar, de reutilizar, tiene consecuencias en nuestra realidad profesional más cercana. Fijémonos en el caso de una reciente convocatoria de un plaza de referencista en la biblioteca de la Universidad de Wisconsin, Whitewater's Andersen (Andersen Library, 2011), en la que se valoran positivamente las características de entusiasta, flexible y emprendedor en el perfil de bibliotecario formador en competencias informáticas e informacionales. Ya no solo se nombra la ALFIN como requerimiento para el bibliotecario, sino que las competencias tecnológicas aparecen como imprescindibles para su trabajo de formador. 


\section{5. ¿Por qué tantas alfabetizaciones?}

A lo largo de este artículo, han ido surgiendo distintos tipos de alfabetizaciones: informacional, mediática, digital, crítica, en medios sociales. Puede verse una clasificación más compleja de los distintos tipos de alfabetizaciones, en el sitio web Noodles Tools (http://www.noodletools.com/debbie/literacies/).

Ante la necesidad de denominar las nuevas necesidades en alfabetización, se ha optado bien por unir varios términos ya existentes o mediante la aparición de otros nuevos. En el primer caso, podemos citar como ejemplo el término propuesto por la UNESCO, Alfabetización digital y mediática (Media and Information Literacy MIL), y para el segundo, un nuevo movimiento que defiende el término Transliteracy (Wilkinson, 2011) en inglés, y alfabetizaciones múltiples en español.

Badke (2009) de la Trinity Western University, explicaba en su columna InfolitLand, los riesgos de afrontar determinados tipos de alfabetizaciones de forma independiente. En el caso de la alfabetización informacional, mediática y en TIC, considera que las tres van evolucionando y se mueven hacia la convergencia, hasta el punto de que sus límites se pueden considerar difusos.

La alfabetización mediática se vuelve imprescindible desde el momento en que los media rodean nuestras vidas, siendo necesario saber acceder a ellos y evaluarlos, pero cada vez más, saber generarlos, crear contenidos, que por otro lado es la base de nuestra cultura actual. Y esto afecta tambien a temas de propiedad y ética y de producción y comunicación. Las TIC abarcan las competencias tecnológicas, imprescindibles por un lado para acceder a la información, pero tambien para generar contenidos en cualquier soporte.

Todas estas alfabetizaciones constituyen silos, cada una con sus defensores y con argumentos bien definidos, cada una fiel a su propia cultura y ecosistema. Sin embargo cada medio está evolucionando en función de los otros, y en la misma dirección, interactuando entre ellos. Los diferentes medios están invadiendo todas las alfabetizaciones, a las que solo se puede acceder con competencias informáticas o tecnológicas, necesarias por otro lado para generar los contenidos en los distintos medios. Sin embargo, tan solo con tecnología, no se puede decir que la sociedad esté alfabetizada, como pretenden hacernos creer todas las políticas gubernamentales que buscan convertirnos en ciudadanos digitales con ordenadores, redes, aulas informáticas, pizarras digitales o dispositivos móviles. Las competencias propias de la gestión de la información se hacen entonces imprescindibles, si bien, matizadas y superadas por las nuevas formas de consumir, generar y compartir que han impuesto las herramientas y aplicaciones sociales, teniendo siempre como base la tecnología. 


\section{La alfabetización informacional y la web social}

Desde el punto de vista de la Biblioteconomía, vamos a ver de qué manera afectan las otras alfabetizaciones a la ALFIN. Sin lugar a dudas, gran parte de los cambios que hemos visto, se deben al impacto de la web 2.0 en las distintas alfabetizaciones.

La alfabetización en información surge de las responsabilidades bibliotecarias de la formación de usuarios en la búsqueda de información. Se trata de formar en las capacidades o habilidades necesarias para identificar una necesidad de información, determinar los mejores recursos para satisfacer esa necesidad de información, obtener la información relevante, evaluarla y usarla de forma ética y legal.

Las bibliotecas se han adaptado siempre al entorno cambiante en el que han vivido. De formación de usuarios se dio el paso a la Alfabetización Informacional, y desde hace ya varios años se están enfrentando a los cambios disruptivos que provocan la tecnología y la web social.

Dunaway (2011a) aborda el impacto de la web 2.0 en la ALFIN desde la perspectiva de la evaluación crítica de los aspectos políticos y sociales de la producción de la información, convirtiendo al usuario en productor activo en la creación de información y conocimiento. Sin embargo, tan solo plantea el impacto de la web 2.0 en el aprendizaje de las competencias informacionales desde el punto de vista de la multiplicidad de herramientas y aplicaciones que aportan al formador, como herramientas de aprendizaje. Es decir, aborda el uso de las herramientas de la web social desde la perspectiva de una mejor enseñanza de las competencias informacionales, desde el punto de vista de las oportunidades que ofrecen estas tecnologías.

Muchas bibliotecas han incluido entre sus contenidos en sus planes de ALFIN, las aplicaciones y distintas plataformas de la web social, pero lo han afrontado únicamente desde el punto de vista de la tecnología. En este sentido han dado un paso significativo, pero tan solo hacia la integración de competencias tecnológicas.

Actualmente, la práctica de la ALFIN en su perspectiva tradicional no tiene en cuenta la revolución que ha supuesto la forma en la que se está produciendo la información y el conocimiento en el entorno de la web 2.0. Las bibliotecas en gran medida, no han entendido que para los contenidos que tradicionalmente se incluyen en la ALFIN, es de vital importancia integrar los que afectan directamente a los procesos de la misma, y se encuentran en la web social. No se trata tan solo de conocer y usar las tecnologías y plataformas de la web social, se trata de integrarlas en los procesos básicos de la gestión de la información, se trata de modificar la forma en la que enseñamos a buscar información, la forma en la que enseñamos a evaluar, a gestionar la información, y comunicarla. El uso de estas aplicaciones no sería completo si no se trabajan con ellas otras competencias como la colaboración, la participación, la conversación, la creación de contenidos y en comunidad, la gestión de la privacidad, la reputación 
e identidad digital, la evaluación y el espíritu crítico y reflexivo, etc. Afecta a todas las competencias básicas de la ALFIN, y afecta sobre todo a la actitud con la que enseñamos y aprendemos. Se trata básicamente, de tener una actitud flexible y abierta (González, 2010).

Las competencias necesarias que demanda esta nueva sociedad digital y en red que hemos visto, no aparecen incluidas o no se tratan con la necesaria profundidad en los tradicionales planteamientos de la ALFIN. Por ejemplo,

- la creación y generación de contenidos multimedia, producir la información con los nuevos parámetros colaborativos de la web social, en los distintos formatos multimedia que son la base de la web social (sonoros, audiovisuales, gráficos);

- participar en la red, tener las pautas y claves necesarias para participar en un entorno multimedia y en red, por lo que hay que educar para esa participación;

- trabajar en grupo y a distancia, en proyectos, de forma colaborativa, multidisciplinar;

- remezclar, reutilizar, redistribuir, en el sentido en el que se expresan Lara (2011a) y Garaizar (2011);

- opinar, comentar, contribuir, compartir información en abierto, aportar nuevas ideas a la inteligencia colectiva, participar en la conversación que se produce en la red, de forma responsable;

- reconocer los méritos del otro respetando sus contribuciones, siendo éticos y legales;

- construir una identidad digital personal y profesional.

Buscar información ya no es lo mismo, como tampoco lo es organizarla o comunicarla, porque la colaboración, la participación, la generación de contenidos y opiniones ocupa un protagonismo que antes no tenía en la visión tradicional de la gestión de la información. El mismo proceso de evaluación se vuelve crítico en el entorno social. Las habilidades necesarias para saber evaluar la información que encontramos en la web y que hoy se exigen, no coinciden en muchos casos con las que normalmente los bibliotecarios enseñan en sus cursos de ALFIN.

La información se vuelve rápidamente obsoleta y para encontrar una información actualizada hay que moverse muy bien por las redes y por las redes de colegas, de profesionales. El networking es un aspecto fundamental de la ALFIN que, por otro lado, no se suele incluir en sus programas de formación (Farkas, 2011).

Luo (2010) y en relación al uso que las bibliotecas están haciendo de las aplicaciones y herramientas de la web social en sus actividades de formación en competencias de gestión de la información, afirma que las bibliotecas están haciendo uso de estas tecnologías de forma activa, en sus actividades formativas, según una jerarquía de tres niveles: en un primer nivel, aproximadamente del 
4\%, los bibliotecarios usan estas plataformas para sus propios fines, pero no involucran a sus estudiantes en el uso de estas herramientas; en un segundo nivel del $84 \%$, se usan estas herramientas únicamente para ofrecer contenidos a los estudiantes o para interactuar con ellos a través de estas plataformas; en el tercer nivel del 38\%, los bibliotecarios integran los contenidos de la web social para ilustrar, ampliar, actualizar, contextualizar y modificar los conceptos básicos de la ALFIN, a la luz de las distintas alfabetizaciones, y en el sentido que venimos describiendo.

La American Association of School Librarians (2007), define la Alfabetización Informacional no solo como el uso de recursos para encontrar información, sino que tambien incluye múltiples alfabetizaciones, digital, visual, textual, media, tecnológica, informática. Como consecuencia las normas para el estudiante del siglo xxi incluyen el uso de información tecnológica y medios digitales, promoviendo el pensamiento crítico y el comportamiento ético, así como la participación democrática (Tripp, 2011).

Para Webber (2011) todo es Alfabetización Informacional y como ejemplo señala el caso de "Media and Information Literacy Curriculum For Teachers" de la UNESCO. En este caso, la alfabetización mediática e informacional está relacionada con las funciones que tienen los distintos medios, las bibliotecas, archivos y otras instituciones democráticas y tiene que ver con la evaluación de los contenidos, el pensamiento crítico, o la demanda de servicios de mayor calidad. Desde su perspectiva, gran parte de la alfabetización mediática es ALFIN, aunque los especialistas en media estén más interesados en explorar las políticas y dimensión social de la creación y uso de los media y los especialistas en multialfabetizaciones, en el uso social de la tecnología y las prácticas de alfabetización en jóvenes y a lo largo de toda la vida. Los que están más interesados en el movimiento Transliteracy, lo están en el uso creativo de medios digitales, como nuevos modos de ficción. Pero si se usa para indicar que se está alfabetizado en información en todo tipo de medios digitales, Webber (2011) considera que es parte de la alfabetización informacional, sabiendo que ALFIN se aplica en distintos medios como revistas, Facebook o Second Life.

Para Mackey y Jacobson (2010), que también defienden la permanencia de la ALFIN como aglutinador de las multialfabetizaciones, sin embargo defienden la necesidad de hacer una reconceptualización de la Alfabetización en Información en el ámbito de la MetaAlfabetización para los medios sociales, considerando que la ALFIN debe incluir una referencia específica a los nuevos medios y añadir a sus competencias la capacidad para compartir la información digital.

De Abreu (2007) considera que la alfabetización mediática no es ALFIN. Para él, la alfabetización mediática es la habilidad para acceder, analizar, evaluar y comunicar información en diferentes formatos y formas, promoviendo el pensamiento crítico más allá de los formatos tradicionales, e incluyendo la alfabetización visual y la tecnológica o informática. 
Dunaway (2011b) considera que el conectivismo y la web 2.0, tienen mucho que decir en un intento por redefinir la ALFIN, así como Metaliteracy y Transliteracy son un marco para la comprensión de la alfabetización en información que hace hincapié en la importancia de las comunidades, las conexiones, las redes de información, y las tecnologías de la información.

Para Kymes (2011), la ALFIN y la alfabetización mediática deben ser reconocidas como complementarias e imprescindibles en el curriculum escolar.

También se observa una confluencia de las TIC hacia la ALFIN. En la web "ICT Digital Literacy Portal" (www.ictliteracy.info/index.htm), se pueden ver iniciativas sobre alfabetización en información en todo el mundo, llevadas a cabo desde universidades en EE.UU. hasta la UNESCO. Es interesante en este sentido señalar que el enlace a "What is ICT Literacy?" lleve a la página de la Universidad de Stanford "What is Information Literacy?" Esta página demuestra como las TIC están evolucionando en la misma dirección que la ALFIN.

Para Kenton y Blummer (2010) la definición de alfabetización digital se relaciona a menudo con la ALFIN y Skagen y otros (2008) sugieren que alfabetización digital surge de la unión de ALFIN y alfabetización tecnológica.

La experiencia de los usuarios en la web social demanda una redefinición de la ALFIN, tal y como venimos defendiendo y que nos aproxima a la alfabetización digital. Por un lado, la web social permite a los usuarios conectarse, comunicarse y colaborar e intercambiar conocimiento en procesos colaborativos, a través de múltiples herramientas y tecnologías. Una de sus características más significativa es la creación de información en colaboración: en la web 2.0, los usuarios finales tienen la oportunidad de crear información, y por lo tanto conocimiento. Por otro lado, en la era digital, el panorama del aprendizaje es en red, social y tecnológico. Estos cambios en el ámbito de la información han influido en la forma en la que los estudiantes buscan y sintetizan la información procedente de diversas fuentes (Dunaway, 2011b). Los estudiantes usan las tecnologías para formar sus propios sistemas de aprendizaje, incluidas sus comunidades de aprendizaje, en las que los estudiantes participan creando conocimiento y no solo consumiendo información. La economía de la información en red, que Internet hace posible, permite que los estudiantes hagan uso de una gran cantidad de recursos de información: bases de datos bibliográficas, revistas en acceso abierto, repositorios institucionales y servicios de referencia virtuales, junto a las herramientas de la web social tales como marcadores sociales y etiquetado, herramientas de uso compartido de información multimedia, feeds RSS, recursos peer-to-peer colaborativos y redes sociales.

Las herramientas de la web social se consideran tecnologías que ponen en evidencia como la enseñanza tradicional ya no es pertinente a la forma en la que aprenden los estudiantes y, de forma extensiva, a los contenidos tradicionales de la ALFIN.

Todas estas perspectivas y puntos de vista de destacados expertos han llevado a los bibliotecarios e investigadores a reconsiderar la definición estándar de 
la alfabetización en información y articular nuevos marcos para su conceptualización. Uno de estos marcos, especialmente relevante para la teoría conectivista del aprendizaje, es Transliteracy.

\section{Las nuevas alfabetizaciones: Transliteracy}

Ante tantas alfabetizaciones, surge Transliteracy, definida como la "convergencia de alfabetizaciones". Cuando el individuo pasa de consumidor de información a productor de contenidos, las fronteras entre las distintas alfabetizaciones, informacional, media, digital, informática o tecnológica se vuelven borrosas. Transliteracy se define como la habilidad para leer, escribir e interactuar en un amplio rango de plataformas, herramientas y medios, desde el canto a la oralidad, desde los manuscritos impresos, los media, hasta las redes sociales (Ipri, 2010).

Pero además, tras el concepto de Transliteracy se perfilan tambien una serie de claves que tienen que ver con una actitud flexible, de adaptación y constante cambio y transformación, y una disposición a adoptar prácticas innovadoras y creativas. Transliteracy es ese paraguas que da cabida a las distintas alfabetizaciones y canales de comunicación, que requieren de una participación más activa y a través de múltiples plataformas, que acoge tanto los mensajes lineales como no lineales (Andretta, 2009). La clave está en la idea de aprendizaje y creación colectiva frente a lo individual (Suárez, 2010).

Ryan Nadal, uno de los autores del informe llamado a constituir la estrategia digital de Canadá, "Digital Literacy in Canada: From Inclusion to Transformation" (http://www.media-awareness.ca/english/corporate/media_kit/reports-publications.cfm), subraya que la idea fundamental de Transliteracy es su capacidad para adaptarse. Se trata de crear un programa de alfabetización que no dependa de modos o espacios (Karp, 2010)

Para Ipri (2010), tras la idea de Transliteracy se encuentra la capacidad de interpretar a través de la interacción de todas las alfabetizaciones, en medios, textuales, visuales, digitales, etc. Sin embargo, aunque su objetivo no era el mundo bibliotecario, Ipri insta a las bibliotecas a seguir los desarrollos de este concepto porque gran parte de él afecta al corazón de la biblioteconomía. En la medida en la que se desarrolle este concepto, los bibliotecarios deberían incorporar estas nuevas ideas a la manera en la que forman a sus usuarios en el acceso, y producción de la información. Los aspectos sociales de la Transliteracy pueden mejorar el trabajo creando sistemas robustos para compartir conocimiento, y pueden mejorar la experiencia del usuario otorgándole un papel en la construcción de la información. 


\section{Hacia dónde vamos: algunos ejemplos de prácticas de alfabetización digital}

Desde el punto de vista de la práctica habitual en nuestros entornos profesionales, se suele identificar competencia digital con TIC, Tecnologías de la Información y la Comunicación, como ya vimos al comienzo de este artículo.

Ponemos como ejemplo el certificado ACTIC impulsado por la Generalitat de Cataluña, que acredita la competencia digital, entendiendo por tal, la combinación de conocimientos, habilidades y actitudes en el ámbito de las tecnologías de la información y la comunicación. En este procedimiento, las bibliotecas públicas del sistema de bibliotecas de la Generalitat de Cataluña, se están convirtiendo en centros colaboradores ACTIC para la certificación de competencias exclusivamente TIC, mediante la puesta a disposición de la ciudadanía de un espacio adecuado para la realización de la prueba correspondiente.

En este mismo sentido encontramos la iniciativa de los centros Guadalinfo, para los que competencia digital es la habilidad de escribir y leer con un nuevo lenguaje, el propio de los medios tecnológicos y audiovisuales. Esta definición se encuentra en EduKanda (http://www.edukanda.es/mediatecaweb/data/zip/ 958/page_03. htm), el repositorio web de la Consejería de Economía, Innovación y Ciencia de la Junta de Andalucía, que permite compartir recursos formativos sobre la Sociedad de la Información y el Conocimiento.

Sin embargo, la competencia digital tambien se está identificando con multialfabetización y el concepto de Educación Expandida que Lara (2011b) define como "las nuevas formas de educación que incorporan y se adaptan a los procesos sociales que ha traído consigo Internet, como la nueva cultura digital, que se basa en la organización en red, el trabajo en equipo, el copyleft, licencias que permiten que cualquier usuario use, modifique y redistribuya un trabajo, siempre que se mantengan estas mismas condiciones de utilización y difusión. Procesos que hasta ahora quedaban fuera de los sistemas educativos convencionales". En este sentido podemos hablar de los proyectos de la EOI, la Escuela de Organización Industrial (http://www.eoi.es). A través de su Plan Estratégico EOI 2010, se definen los principios de la cultura digital y una metodología de escuela abierta, digital y colaborativa. "Desde el año 2009 se han puesto en marcha varios proyectos tanto en el ámbito de los contenidos (repositorios open access en software libre, publicaciones con licencias Creative Commons, incorporación de blogs de alumnos, diseño curricular por proyectos, clases abiertas por streaming, etc.), como en la participación de sus comunidades (fomento de identidades digitales de visibilidad profesional, tablones digitales para crowdsourcing y conversaciones abiertas en redes sociales con alumni), y en la canalización de su interacción a través de tecnologías libres y móviles que rompen el aula y expanden la experiencia de aprendizaje más allá de sus límites espacio-temporales (mobile learning con tablets Android)" (Lara, 2011b). 
En un terreno más específicamente bibliotecario, nos encontramos con los siguientes ejemplos de Alfabetización digital y de generación de contenidos digitales locales.

\subsection{CI2 de CRUE/TIC/REBIUN}

CI2 es el acrónimo de competencias informáticas e informacionales y surge en la Comisión mixta intersectorial CRUE-TIC (Comisión Sectorial de las Tecnologías de la Información y las Comunicaciones) y REBIUN (Red de Bibliotecas Universitarias), como una propuesta de trabajo conjunta que tiene como objetivo la incorporación de estas competencias transversales en las universidades españolas, pero sobre todo, como la evolución necesaria para adaptar las competencias informacionales al ámbito digital. Esta iniciativa es el resultado del acuerdo entre bibliotecas universitarias y Servicios TIC de las Universidades para trabajar en colaboración con el objetivo de formar a sus comunidades universitarias en las competencias clave del mundo digital.

El grupo de trabajo de CI2, compuesto por bibliotecarios e informáticos de varias Universidades, ha elaborado un conjunto de documentos que sirve de base a esta idea, así como unos vídeos promocionales y un decálogo de las CI2 (http://www.usc.es/export/sites/default/es/congresos/crai/reservas/CI2_en_la_U niversidad.pdf). En ese decálogo no se hace diferencia entre unas y otras competencias sino que van entrelazadas, mezcladas, como si de una sola competencia se tratara, sin establecer diferencias ni fronteras entre ellas.

En la recién estrenada web (www.ci2.es), pueden verse los objetivos del grupo de trabajo, así como los materiales de aprendizaje que están elaborando.

Como proyecto en marcha, este grupo está llevando a cabo una encuesta, que dibuje el mapa de las CI2 en las universidades españolas, en cuanto a contenidos y prácticas que se llevan a cabo en las Universidades españolas, así como propuestas de futuro, y focalizando en los estudiantes de grado en primera ins-

FIGURA 6

\section{Web de CI2}

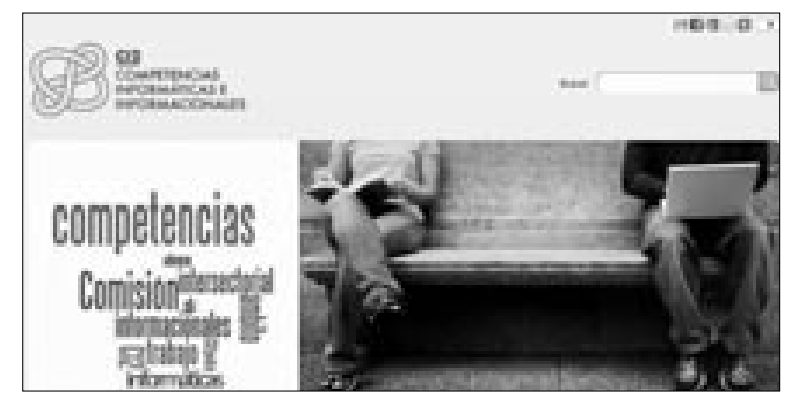

Rev. Esp. Doc. Cient., N. ${ }^{\circ}$ Monográfico, 17-45, 2012. ISSN: 0210-0614. doi: 10.3989/redc.2012.mono.976 
tancia. Los resultados de dicha encuesta se harán públicos en las próximas jornadas CRAI de REBIUN, en junio de 2012.

De las Universidades españolas que ya ofrecen formación curricular en CI2, destacamos la Univeristat Pompeu Fabra (UPF) (http://www.upf.edu/bibtic/serveis/formacio/sessions.html), la Universidad de Sevilla (http://bib.us.es/cursos_orientacion/) y la Universidad de Alicante (http://web.ua.es/es/ci2/curso-ci2basico.html).

\subsection{Biblioredes: Capacitación y Contenidos Digitales Locales}

Biblioredes es una iniciativa de la DIBAM, la Dirección de Bibliotecas, Archivos y Museos del gobierno chileno, que se ha convertido en un referente en el campo de las bibliotecas públicas en todo el mundo, especialmente por su significativo papel en la formación en competencias digitales de la ciudadanía, así como en el fomento a la creación de contenidos locales digitales.

Los objetivos que se han perseguido en este proyecto han sido tres: 1) promover el acceso libre y gratuito a ordenadores conectados a Internet por parte de la comunidad que atienden las bibliotecas públicas; 2) desarrollar las competencias y destrezas digitales básicas en los usuarios de estas bibliotecas, y 3) promover la generación de contenidos locales en formato digital, en especial a través del apoyo a la creación de espacios web por los propios usuarios.

Estos tres objetivos han buscado hacer de las bibliotecas públicas de Chile espacios de acceso a las TIC para los sectores de menores recursos de la sociedad chilena, promoviendo su integración en redes y comunidades virtuales y dotándoles de las habilidades necesarias para gestionar la información que necesitan. Como complemento a este ingente trabajo, Biblioredes cuenta con otro programa dedicado a la formación y apoyo en la creación de contenidos digitales locales. El objetivo de este programa es el registro en formato digital de contenidos culturales sobre Chile. (http://www.contenidoslocales.cl/mensaje/16/ bienvenido). Se trata de que los ciudadanos aporten contenidos propios, conocidos, cercanos, que pueden ser también comentarios sobre hechos históricos, o eventos sociales, artísticos, antropológicos, o cualquier otro tipo de manifestación que se conozca, propia de su localidad, y que de otra manera se perderían o llegarían a ser difícilmente conocidos.

Además de este tipo de memoria local, se busca tambien aumentar la visibilidad de aquellas iniciativas o actividades económicas que buscan la promoción de proyectos innovadores que se han puesto en marcha en espacios alejados o en menor medida conectados con los canales habituales de promoción local de actividades comerciales (Abbagliati, 2007).

Especialmente significativo ha sido el trabajo desarrollado en el ámbito de los sitios web con contenidos locales creados por los propios usuarios de las bibliotecas. 


\subsection{Plan Alba: Formación en competencias digitales y Apoyo a la creación de Contenidos Digitales Locales}

Desde el año 2009, el Servicio del Libro, Bibliotecas y Centros de Documentación de la Consejería de Cultura de la Junta de Andalucía impulsa el Plan Alba de formación en competencias digitales de los bibliotecarios de la red de bibliotecas públicas de Andalucía, con el objetivo de que formen en estas mismas competencias a sus comunidades locales. Los contenidos formativos incluyen competencias tecnológicas y de herramientas de la web social pero también competencias en gestión de la información en un entorno digital, compartido y en red (González, 2011).

Hasta noviembre de 2011 se han formado alrededor de 700 bibliotecarios en cursos presenciales en las 8 provincias andaluzas y tambien en formato virtual. En el año 2011, se ha continuado con la oferta de los cursos de formación en las dos modalidades. De forma complementaria, se han impartido microcursos virtuales de aprendizaje específico de tecnologías audiovisuales (videos y podcast) y de otras herramientas de la web social como Flickr, Youtube, wikis, blogs, etc., para incrementar las habilidades en el uso de estas herramientas y tecnologías. Todos los contenidos de las actividades formativas se encuentran en la wiki del Plan Alba (http://planalba.pbworks.com/).

A finales de 2011, el Plan Alba asume un nuevo objetivo, el Apoyo a la Creación de Contenidos Digitales Locales, siguiendo el modelo de Biblioredes y buscando la sinergia con otros proyectos de índole andaluz como Wikanda, EduKanda o Guadalinfo. El Plan Alba de contenidos digitales locales representa un nuevo desafío para el proyecto Plan Alba de Alfabetización digital: la necesidad de establecer un espacio para contenidos culturales locales, que den cuenta de las posibilidades y oportunidades que las bibliotecas ofrecen a su comunidad para publicar y exponer las distintas manifestaciones del quehacer cultural y social de los diversos actores, sean estos singulares y/o colectivos.

Los objetivos por lo tanto que sustentan el Plan Alba en su conjunto son, en esencia, dos: 1) desarrollar las competencias en gestión de la información, en el uso de las tecnologías de la web social y en la edición digital, en los bibliotecarios de la red de bibliotecas públicas de Andalucía para que a su vez estos formen a sus comunidades en esas mismas competencias; 2) y con este plan de contenidos digitales locales, el objetivo es promover la generación de contenidos locales en formato digitales, en especial a través del apoyo a la creación de sitios web por los propios usuarios de la comunidad andaluza.

Por lo tanto su fin es generar los medios necesarios para que las comunidades locales construyan, administren y utilicen contenidos, productos y servicios digitales, que promuevan su presencia global en la red. Este segundo punto tiene a su vez dos ejes de trabajo o líneas de acción: 
1. Generar los instrumentos y la convocatoria para el desarrollo de contenidos digitales locales por sus comunidades, siendo el modelo inicial la comunidad de los responsables de bibliotecas públicas provinciales y encargados del proyecto en las bibliotecas.

2. Diseñar, poner en funcionamiento, administrar y difundir un portal web dinámico que integre los contenidos, servicios y productos de pertinencia y generación local para las comunidades asociadas a la red de bibliotecas públicas de Andalucía.

El equipo que coordina los Contenidos Digitales Locales, debe organizar la formación, elaborar los materiales y evaluar los contenidos aportados; estará formado por bibliotecarios de la red de bibliotecas públicas de Andalucía, y en su composición deben figurar tanto bibliotecarios de las Bibliotecas públicas como municipales.

En todo caso serán los usuarios los que desarrollen y publiquen los contenidos digitales locales, para lo cual contarán con un espacio virtual para la expresión de contenidos comunitarios, a través de formatos digitales como páginas y sitios web, galería de imágenes, vídeos, podcasts, archivos digitales y otros, que permitan su participación y vinculación con otras iniciativas.

Entre las primeras acciones que se van a acometer en el 2012, se encuentra el proyecto piloto que se va a desarrollar en la Biblioteca Provincial de Huelva, y el éxito de este modelo se replicará en el resto de las provincias andaluzas.

\section{Conclusiones. Hacia una colaboración radical}

Nos guste o no, tenemos que asumir que nuestros hábitos de creación y consumo cultural están experimentando una transformación radical. En los próximos años tendremos un acceso ilimitado a cantidades inmensas de contenidos digitales creados en gran parte por los ciudadanos, lo que conllevará una reorganización de la sociedad.

Ante estas nuevas formas de acceder y consumir la cultura, las entidades del sector cultural (editoriales, museos, centros docentes y bibliotecas, entre otras) deberían reflexionar sobre cuál será su papel para crear una sociedad digital más culta, responsable y participativa (Celaya, 2011).

Las bibliotecas, especialmente las universitarias, están realizando grandes esfuerzos por integrar la formación en competencias informacionales dentro de los currículos universitarios. Sin embargo, en sus planes formativos no introducen la formación digital que hoy día se necesita más allá de la formación con fines de investigación. En la sociedad de la abundancia de la información, la alfabetización informacional debería centrarse en ayudar al individuo a desarrollar habilidades que les faciliten resolver problemas y la toma de decisiones a lo largo de toda su vida, no solo de cara a una investigación científica (Farkas, 2011). 
La formación que las bibliotecas ofrecen, debe dar los pasos necesarios para confluir hacía la alfabetización mediática, ya que los medios constituyen el lugar común, especialmente, de los jóvenes. Las competencias mediáticas incluyen, como hemos visto, un amplio abanico de competencias sociales y culturales, relacionadas con la propiedad y la remezcla de medios, que contribuyen a la producción colaborativa y distribuida, la circulación y distribución de media y la actitud crítica. En el terreno de las bibliotecas universitarias, cada vez es mas necesario que los jóvenes desarrollen competencias analíticas, sociales, técnicas y creativas, que les van a ser necesarias para usar, crear y compartir media de forma responsable social y éticamente (Tripp. 2011).

Desde el punto de vista de la tecnología, de igual forma, sin una formación adecuada en las competencias informáticas y tecnológicas, el estudiante, el individuo, no tendrá acceso a la información que se está produciendo en las redes, en formato digital, no tendrá acceso a las herramientas que le van a permitir integrarse y participar en la sociedad actual. Las competencias tecnológicas no lo son todo pero si son el primer paso para la alfabetización, constituyen el vehículo necesario para llegar a la información y al conocimiento.

Las tecnologías y aplicaciones sociales serán la clave para entender, participar y aprender en una cultura cada vez más social y participativa, donde la lectura es social (Cordón, 2010), la escritura es social, el aprendizaje es social, la publicación es social, y la evaluación de la calidad tambien es social.

Se trata por tanto de algo de suma importancia para las bibliotecas en general, pero especialmente para las universitarias, ya que entre sus objetivos debe estar la conexión con los sistemas de aprendizaje de los estudiantes y la mejora de sus competencias digitales (Dunaway 2011b).

Se hace imprescindible por tanto la colaboración. No se trata de incluir todas las competencias, todas las alfabetizaciones, en un único rango de estas, dentro de una existente con la cual, todas o casi todas las alfabetizaciones tienen que ver. Podríamos decir que todas son dependientes entre sí, y que sin lugar a dudas, tanto la tecnología, como los medios sociales y lo multimedia, han introducido diferencias y nuevos conceptos que obligan a diseñar una nueva alfabetización y el término que parece aglutinarlos y se considera más aceptado, es alfabetización digital.

Por otro lado, esta alfabetización para un mundo digital, conectado y en red, debe incluir a muchos tipos de profesionales, como son los docentes, pero también bibliotecarios, especialistas en medios, pedagogos, informáticos, por lo que no puede ser una alfabetización relacionada en exclusiva con una profesión. La colaboración se impone, y haciendo partícipes cada vez más, a los propios usuarios.

Cuando en el terreno de las bibliotecas universitarias surgió el concepto de CRAI, como término evolucionado de las bibliotecas, lo que se pretendía era el nacimiento de un nuevo concepto de servicio que aglutinara a todos los profesionales en torno al usuario. Todos los servicios debían confluir en un único es- 
pacio en el que el usuario encontrara todas sus necesidades de información, producción y comunicación de la información, cubiertas y perfectamente atendidas por profesionales de distintas ramas: bibliotecarios, informáticos, expertos en medios audiovisuales, en publicación, etc. La biblioteca dejaba de ser lo que había sido hasta ese momento para formar parte de un colectivo de profesionales al servicio del usuario, de sus necesidades de información.

Proponemos algo similar en relación a la alfabetización informacional, que deje de ser lo que ha sido hasta ahora para integrarse en un conjunto de alfabetizaciones, mediática, tecnológica, informática, social, crítica, etc., en beneficio de la formación del usuario en las competencias que le son básicas en la sociedad actual.

No es tan importante decidir cual es la alfabetización que debe incluir a las demás alfabetizaciones, ni qué profesionales son los que deberían responsabilizarse de esta tarea, ampliando y extendiendo sus fronteras hasta límites no previstos, sino centrarnos en el usuario, en el individuo, en sus necesidades de formación, de adquisición de unas habilidades imprescindibles, para el cual estas diferencias entre competencias o profesionales son transparentes, sencillamente no existen. El objetivo es el usuario, independientemente del profesional que mejor vaya a formarlos en esas necesidades evidentes de competencias para estar alfabetizado en un mundo digital y en red.

Para Farkas (2011), en la era de la colaboración y la participación se impone que los profesionales de diferentes ramas trabajen en colaboración, aportando cada sector lo que sabe hacer y cuyo único centro de mira sea la formación de la comunidad a la que servimos.

Queremos finalizar este artículo nuevamente con las palabras de Lara (2011b): "Vivir en una sociedad en red nos obliga a trabajar en un entorno en constante cambio. Cada día se vuelve más importante aprender a desarrollarnos como profesionales digitales, con capacidad para colaborar de forma abierta con otras personas, procesar información compleja y tomar decisiones responsables en el menor tiempo posible. Todo ello en cualquier momento y en cualquier lugar».

\section{Bibliografía}

Abbagliati Boïls, E. (2007). ¿Patrimonio 2.0? Contenido Local, Tecnología y Comunidad desde la Experiencia de Biblioredes. Actas IX Seminario sobre Patrimonio Cultural. Santiago de Chile, 22 de noviembre.

Andersen Library, University of Wisconsin-Whitewater (2011). Reference \& Instructional Technology Librarian. Whitewater, WI. Jobslift. <http://usa.jobslift.com/job_referenceinstructional-technology-librarian-andersen-library-university-of-wisconsin-whitewate758883.html> [fecha de consulta: 12/11/2011].

Andretta, S. (2009). Transliteracy: take a walk on the wild side. Proceeding World Library and Information Congress: 75th IFLA General Conference and Council. 23-27 August, 
Milán, Italy <.http://nlabnetworks.typepad.com/transliteracy/Andretta_Transliteracy. pdf $>$ [fecha de consulta: 02/12/2011].

Area Moreira, M. (2011). Educar para la cultura líquida de la web 2.0. Apuntes para un modelo de alfabetización digital. Actas I Congreso Internacional sobre Educación Mediática y Competencia Digital. Segovia, 13-15 octubre. <http://www.educacionmediatica.es/comunicaciones/Eje\%204/Manuel\%20Area\%20Moreira.pdf> [fecha de consulta: 02/12/2011].

Badke, W. (2009). Media, ICT, and Information Literacy. Online, vol. 33 (sept-oct.), 47-49.

Breeding, M. (2011). Actuales y futuras tendencias en Tecnologías para Unidades de Información: Una perspectiva internacional. Congreso Innovatics 2011. <http://www.librarytechnology.org/ltg-displaytext.pl?RC=16224> [fecha de consulta: 02/12/2011].

Celaya, J. (2011). Escasa creación original, colaborativa, participativa. Telos, Cuadernos de Comunicación e Innovación, n. ${ }^{\circ}$ 89. <http://sociedadinformacion.fundacion.telefonica.com $/$ seccion $=1266 \&$ \&idioma $=$ es_ES\&id $=2011072809100001 \&$ activo $=6$. do $>[$ fecha de consulta: 02/12/2011].

Cobo Romaní, C. (2011), Aprendizaje y alfabetismo invisible ¿Por qué no basta con ser 2.0? Congreso Universidad 2.0: reiniciando el modelo de aprendizaje en la Educación Superior. Universidad Internacional Menéndez Pelayo. Santander. Septiembre, 7. $<$ http://ergonomic.wordpress.com/2011/09/07/no-basta-con-2-0/> [fecha de consulta: 02/12/2011].

Congreso Internacional Educación mediática \& Competencia digital (2011). La Cultura de la participación. Comunicaciones. 13-15 de octubre. Segovia. <www.educacionmediatica.es/comunicaciones> [fecha de consulta: 02/12/2011].

Cordón-García, J. A. (2010). De la lectura ensimismada a la lectura colaborativa: nuevas topologías de la lectura en el entorno digital. En: Gómez Díaz, R. y Agustín Lacruz, M. C. (eds.), Polisemias visuales. Aproximaciones a la alfabetización visual en la sociedad intercultural. Salamanca: Universidad de Salamanca, pp. 39-84 < http://eprints. rclis.org/bitstream/10760/15441/1/lecturaensimismada.pdf $>$ [fecha de consulta: 02/12/2011].

De Abreu, B. S. (2007). Teaching media literacy: A how-to-do-it manual and CD-ROM. New York: Neal-Schuman Publishers

Dunaway, M. (2011a). Web 2.0 and Critical Information Literacy. Public Services Quarterly, vol. 7 (3-4), 149-157

Dunaway, M. (2011b). Connectivism Learning theory and pedagogical practice for networked information landscapes. Reference Services Review, vol. 39 (4), 675-685.

Farkas, M. (2011). Information Literacy 2.0. American Libraries, The magazine of the American Library Association. 01/11/2011 <http://americanlibrariesmagazine.org/columns/ practice/information-literacy-20> [fecha de consulta: 02/12/2011].

Garaizar, P. (2011). La cultura de la remezcla. Curso de verano Content Curator. San Sebastian, 5-6 septiembre. <http://www.slideshare.net/txipi/la-cultura-de-la-remezcla9147229> [fecha de consulta: 02/12/2011].

Giones Valls, A.; Serrat i Brustenga, M. (2010). La gestión de la identidad digital: una nueva habilidad informacional y digital. BiD: textos universitaris de biblioteconomia $i$ documentació, juny (24). <http://www.ub.edu/bid/24/giones2.htm> [consulta: 16-12-2011].

Rev. Esp. Doc. Cient., N. ${ }^{\circ}$ Monográfico, 17-45, 2012. ISSN: 0210-0614. doi: 10.3989/redc.2012.mono.976 
González Fernández-Villavicencio, N. (2010). Helping students become literate in a digital, networking-based society: A literature review and discussion. The International Information \& Library Review, vol. 42 (2, June), 124-136

González Fernández-Villavicencio, N. (2011). Plan Alba: Alfabetización Digital en Bibliotecas Públicas de Andalucía. Sevilla, Junta de Andalucía, Consejería de Cultura. ISBN: 978-84-9959-058-5. < http://www.juntadeandalucia.es/cultura/web/html/sites/consejeria/areas/biblioteca/Galerias/Adjuntos/Plan_ALBA_29_09_11.pdf> [consulta 27/11/ 2011].

Ipri, T. (2010). Introducing transliteracy. What does it mean to academic libraries? November College \& Research Libraries News, vol. 71 (10), 532-567<http://crln.acrl.org/ content/71/10/532.full.pdf+html> [fecha de consulta: 02/12/2011].

Karp, J. (2010). What Is This Buzz Word "Transliteracy»? A Q\&A with Ryan Nadel. Spotlight, $10.25 .10<$ http://spotlight.macfound.org/featured-stories/entry/what-is-this-buzzword-transliteracy-a-qa-with-ryan-nadel/> [fecha de consulta: 02/12/2011].

Kenton, J.; Blummer, B. (2010). Promoting Digital Literacy Skills: Examples from the Literature and Implications for Academic Librarians, Community \& Junior College Libraries, vol. 16 (2), 84-99

Kymes, A. (2011). Media Literacy and Information Literacy: A Need for Collaboration and Communication. Action in Teacher Education, vol. 33, 184-193

Lara, T. (2011a). Alfabetizar en la cultura digital. Blog Tiscar.com. 17/7/2011 <http://tiscar.com/2011/07/17/alfabetizar-en-la-cultura-digital/> [fecha de consulta: 02/12/2011].

Lara, T. (2011b). Cómo reinventar la Educación Superior desde lo abierto. Blog Tiscar.com 11/9/2011 <http://tiscar.com/2011/09/11/como-reinventar-la-educacion-superior-desde-lo-abierto/> [fecha de consulta: 02/12/2011].

Luo, L. (2010). Web 2.0 Integration in Information Literacy Instruction: An Overview. The Journal of Academic Librarianship, vol. 36 (1), 32-40. <http://www.sciencedirect.com/ science/article/pii/S009913330900202X> [accessed July 30, 2011].

Mackey, T. P.; Jacobson, T. E. (2010). Re-Conceptualizing Information Literacy as a Metaliteracy for Social Media. Information Literacy Research Seminar. CoLIS 2010: Unity in Diversity. London, June 23 <http://bada.hb.se/handle/2320/6537> [fecha de consulta: $17 / 12 / 2011]$.

Moeller, S.; Joseph, A.; Lau, J.; Carbo, T. (2011). Towards Media and Information Literacy Indicators. UNESCO. Background Document of the Expert Meeting. <http://www. unesco.org/new/fileadmin/MULTIMEDIA/HQ/CI/CI/pdf/unesCo_mil_indicators_background_document_2011_final_en.pdf> [fecha de consulta: 02/12/2011].

OCLC (2011). Libraries at Webscale, a discusión document. Dublin, Ohio USA, OCLC. ISBN: 978-1-55653-438-6. <http://www.oclc.org/reports/webscale/default.htm> [fecha de consulta: 06/12/2011].

Pisani, F.; González Fernández-Villavicencio, N. (2011). Procesar la información Mapa Mental. MindMeister. <http://www.mindmeister.com/es/97701136/procesar-la-informaci-n> [fecha de consulta: 02/11/2011].

Potter, W. J. (2010). The State of media literacy. Journal of Broadcasting \& Electronic Media, 54 (4), 675-696 
Prensky, M. (2011). In the 21st-Century University, Let's Ban (Paper) Books. The Chronicle of Higher Education, December, 6. <http://chronicle.com/article/In-the-21st-Century/129744/?sid=wc> [fecha de consulta: 06/12/2011].

Rainie, L. (2011). Reading, Writing, \& Research in the Digital Age. School Library Journal Reading Summit. <http://www.slideshare.net/PewInternet/2011-9-23-11-teens-readingwriting-researching-school-library-journal $>$ [fecha de consulta: 02/11/2011].

Skagen, T.; Torras M. C.; Kavli, S. M.; Mikki, S.; Hafstad, S; Hunskar. I. (2008). Pedagogical considerations in developing an online tutorial in information literacy. Communications in Information Literacy, 2 (2), 84-98.

Suárez, C. (2010). La formación en red como objeto de estudio. Revista de Universidad y Sociedad del Conocimiento (RUSC), vol. 7 (2). <http://rusc.uoc.edu/ojs/index.php/rusc/ article/view/v7n2-suarez/v7n2-suarez> [fecha de consulta: 02/11/2011].

Tripp, L. (2011). Digital Youth, Libraries, and New Media Literacy, The Reference Librarian, 52 (4), 329-341.

Warlick, D. (2008). Literacy \& Learning in the 21st Century. Professional Page. The Landmark Project. 16 Mar. <http://davidwarlick.com/wordpress/?page_id=61> [fecha de consulta: 02/12/2011].

Webber, S. A. (2011). Information/digital/media literacy. to: ili-l@ala.org date: Wed, Aug 3, 2011 at 18:33 [fecha de consulta: 02/12/2011].

Wilkinson, L. (2011). Transliteracy or Metaliteracy? Libraries and Transliteracy, February, 1. <http://librariesandtransliteracy.wordpress.com/2011/02/01/transliteracy-or-metaliteracy/> [fecha de consulta: 17/12/2011].

Wilson, C.; Grizzle, A.; Tuazon, R.; Akyempong, K.; Cheung, C. (2011). Media and Information Literacy, Curriculum for teachers. Paris, UNESCO. ISBN 978-92-3-104198-3 $<$ http://unesdoc.unesco.org/images/0019/001929/192971e.pdf> [fecha de consulta: $12 / 11 / 2011]$. 